\title{
The association of syphilis with hepatic cirrhosis: a report of six cases and a review of the literature
}

\author{
G. KARMI \\ M.B., M.R.C.P.
}

\author{
J. L. ThIRKETTLE \\ M.B., M.R.C.P.
}

\author{
A. E. A. READ \\ M.D., F.R.C.P. \\ Department of Medicine, Bristol Royal Infirmary, \\ Bristol 2
}

\begin{abstract}
Summary
Among forty-nine patients with cirrhosis admitted to the Bristol Royal Infirmary in the years between 1962 and 1967 inclusive, six cases were found who also had syphilis.

The possible significance of this association is discussed and a short review of the literature presented.

The importance of routine serological testing for syphilis on all cirrhotic patients, particularly male, is stressed.
\end{abstract}

\section{Introduction}

The relationship of syphilis to cirrhosis was of great interest to workers at one time (Symmers, 1916; Le Duc, 1929; Schumacher, 1937; Ratnoff \& Patek, 1943; Hahn, 1943). However, in recent years, the subject has received scant notice. On reviewing the records of forty-nine patients with cirrhosis admitted to the Bristol Royal Infirmary, under the care of one of us (A.E.A.R.), in the period 1962-67, we observed that no less than six had presented with the two diseases combined. It seemed to us, therefore, of interest to record these, review the literature, and explore the possible reasons for the association.

\section{Patients and methods}

All patients with cirrhosis admitted to this unit are routinely asked about past infection with syphilis, and a Wasserman Reaction (WR) is performed. It is obvious that many will deny such infection, and therefore reliance has to be placed on the result of their serology. It is necessary to stress, however, that in view of the existence of the Biological False Positive phenomenon in patients with abnormal plasma protein patterns (Moore, 1956; Brit. med. J. Editorial, 1967), it is likely that a certain number of positive WRs found in cirrhosis will be of this type (Knight \& Wilkinson, 1963). In view of this, it is desirable to proceed to a more reliable test for syphilis, i.e. the Treponema pallidum Immobilization Test (TPI), and this was the procedure used in our six patients following the finding of a positive WR. (In addition, a TPI was performed on twenty patients of the total forty-nine with cirrhosis. In these the result was negative as also was the WR.)

The diagnosis of cirrhosis was established in all the cases but one, who was very ill on admission, by liver biopsy and the biopsies have all been examined by the same pathologist, Dr W. J. Harrison.

All the haematological and biochemical tests were performed in the same laboratory by standard methods.

All the six patients were male and a summary of their clinical data and biopsy reports is presented in Table 1.

\section{Discussion}

Acquired syphilis may affect the liver in a variety of ways. In the secondary stage, it may share in the general spirochaetaemia with the production of granulomatous lesions which have been demonstrated by biopsy (Sherlock, 1963). This is not usually associated with symptoms (Hahn, 1943), but the liver function tests may be transiently abnormal (Bockus, 1965). Also during this stage a form of jaundice, of short duration and good prognosis, sometimes appeared, which often cleared up with arsenical therapy (Hahn, 1943; Stokes, Beerman \& Ingraham, 1945). Although some of these cases were probably due to syringe-transmitted hepatitis, it is unlikely that all of them were, but as no pathology was ever available for examination during the illness the cause must remain speculative (Popper \& Schaffner, 1957; Sherlock, 1963; Bockus, 1965). Very rarely, 'acute yellow atrophy' with a fatal termination occurred in the secondary stage (Stokes 


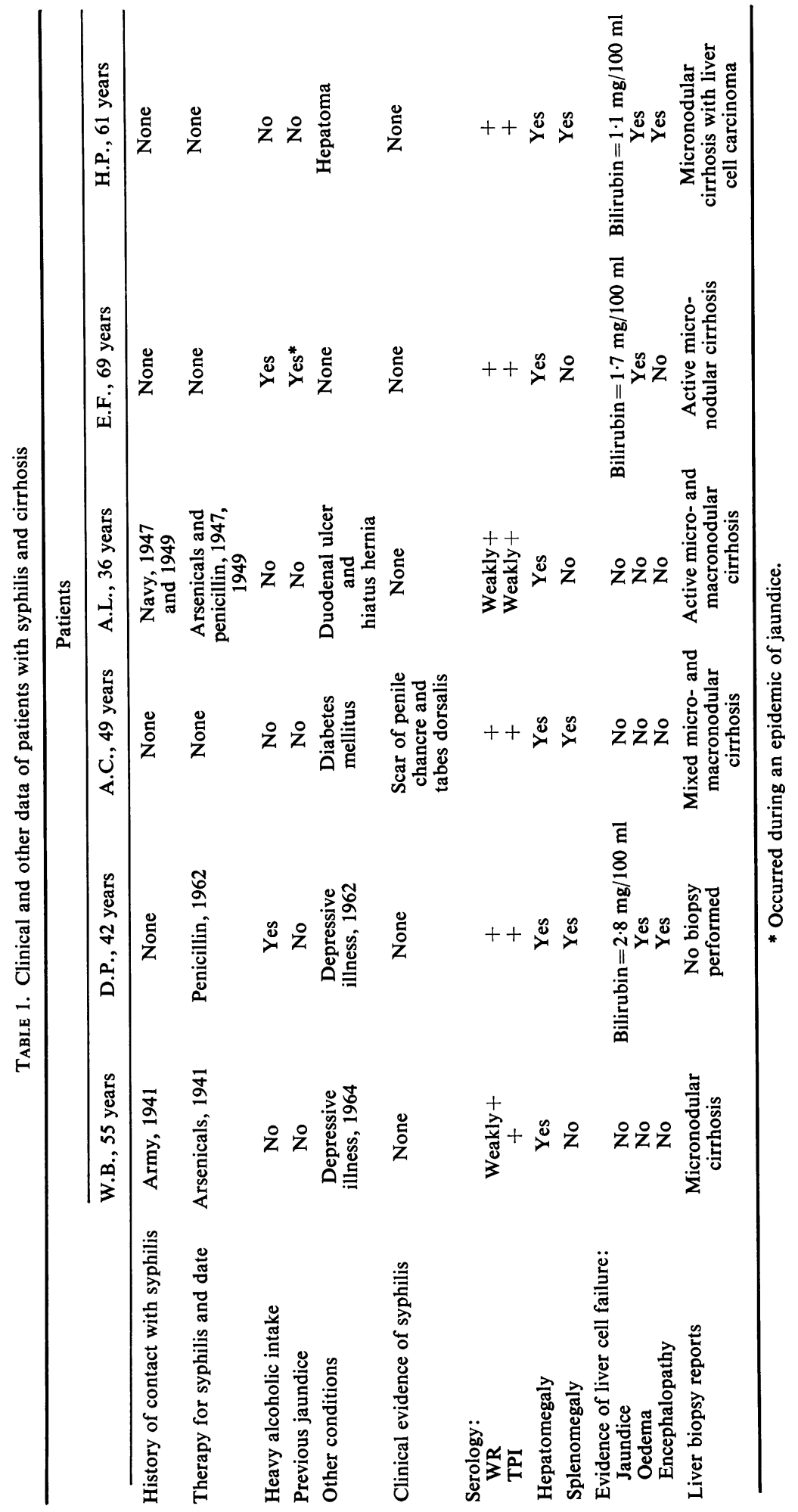


TABLE 2. Percentage syphilis and alcoholism in previous series

\begin{tabular}{lcccc}
\hline \multicolumn{1}{c}{ Series } & Date & No. of patients & $\%$ syphilis & $\%$ alcoholism \\
\hline Frerichs & 1861 & 36 & 18 & 33 \\
Symmers & 1916 & - & 80 & - \\
Le Duc & 1929 & 58 & $60 \cdot 3$ & - \\
Yenikonshian & 1934 & 70 & 12 & None \\
Boles \& Clark & 1936 & 243 & 11 & $34 \cdot 6$ \\
Shumacher & 1937 & 74 & 28 & $35 \cdot 5$ \\
Evans \& Gray & 1938 & 217 & 12 & $26 \cdot 5$ \\
Ratnoff \& Patek & 1942 & 386 & 16 & $53 \cdot 6$ \\
Fleming \& Snell & 1942 & 200 & 16 & $42 \cdot 5$ \\
MacDonald \& Mallory & 1958 & 190 & 23 & 40 \\
Miyai \& Reubner & 1963 & 268 & $15 \cdot 5$ & - \\
Manderson et al. & 1965 & 49 & 10 & $22 \cdot 4$ \\
Present series & 1967 & 49 & $12 \cdot 5$ & 30 \\
\hline
\end{tabular}

et al., 1945) but, as almost all the reported cases had been previously treated with arsenicals (Hahn, 1943), it would seem likely that these were examples of severe viral hepatitis. In tertiary syphilis, the liver may be affected by gummata, either single or more commonly multiple. On healing, the resultant scar formation divides the liver into lobules which can be very large, and the condition is then described as 'hepar lobatum' (Symmers, 1916). The fibrosis associated with gummata sometimes involves radicles of the portal vein leading to portal hypertension (Shapiro \& Weiner, 1951), but on the whole, hepar lobatum is rarely diagnosed in life (Symmers, 1916; Symmers \& Spain, 1946).

In the first half of the century, syphilis was thought to affect the liver in yet another way. In 1945, the concept of 'syphilitic cirrhosis' was firmly accepted by Stokes et al., who thought that the tertiary gummatous process, when diffused, caused such fibrosis as could lead to a fully developed cirrhosis. Two years earlier, however, Hahn had examined the known facts about syphilis and the liver. Among a large number of autopsies, he was only able to find one case of hepatic syphilis with cirrhosis, and, on comparing the incidence of cirrhosis in two large autopsy series of syphilitics and non-syphilitics, he did not consider the difference strikingly significant. He concluded from this and a review of the previous literature that syphilis did not cause cirrhosis per se. This view is shared by modern authorities, and Sherlock states that: 'syphilis and cirrhosis are not related'. Bockus similarly feels that cirrhosis occurring in a syphilitic is more likely to be due to alcoholism, malnutrition or syringe hepatitis than to the syphilis itself.

Nevertheless, an association between the two diseases has been repeatedly noted in the past and remains true at the present time (Symmers, 1916; Le Duc, 1929; Yenikonshian, 1934; Scumacher, 1937; Evans \& Grey, 1938; Ratnoff \& Patek, 1942; Fleming \& Snell, 1942; MacDonald \& Mallory, 1958; Wells \& Lundberg, 1963; Miyai \& Reubner,
1963; Manderson, Patrick \& Peters, 1965). As long ago as 1861 , Frerichs recorded that of thirty-six patients with cirrhosis, six were also syphilitics, an incidence of $18 \%$. Symmers in 1916 found that in what he described as 'recently diagnosed cases of cirrhosis', $80 \%$ had a positive WR. Eleven years later, Le Duc (1929), in a review of 2285 autopsies, found fifty-eight cases of cirrhosis, thirty-four of whom $(60 \%)$ had definite histological evidence of syphilis in other organs. In 1934, Yenikonshian reported on seventy non-alcoholic Moslem cirrhotics of whom $12 \%$ either had a positive history of syphilis or a positive WR. Two years later, Boles \& Clark (1936), reviewing 243 cases of cirrhosis, recorded an $11 \%$ incidence of syphilis, and in the next year Schumacher reported seventy-four autopsy cases of cirrhosis, of whom fifteen ( $28 \%$ ) had been syphilitic. The diagnosis of syphilis was based on either the history, a strongly positive WR, or histological evidence of syphilis in organs other than the liver. By comparison, in a control autopsy series he found an incidence of syphilis of $4.4 \%$, and in twenty-four patients dying of syphilis, only three were found to have cirrhosis also. Evans \& Gray in 1938 reviewing the post-mortem records of 217 patients with cirrhosis, noted that $12 \%$ had had syphilis. A few years later, Ratnoff \& Patek (1942) in their classical paper on the natural history of Laennec's cirrhosis, reported that $16 \%$ of their 386 cases had either a positive history of syphilis or positive serological tests. Fleming \& Snell (1942) in the same year likewise noted a $16 \%$ incidence of syphilis among 200 patients with portal cirrhosis. In 1958, MacDonald \& Mallory analysed 190 autopsies of patients dying of post-necrotic cirrhosis and found that $23 \%$ had either admitted to having had syphilis or had positive serology, whereas the incidence of syphilis in a control group of sixty-one autopsies was $9 \%$. Wells \& Lundberg in 1963 reported that $11 \%$ of all the cirrhotic patients coming to autopsy at their hospital over the previous 14 years had had syphilis. Myai \& Reubner (1963) found that of 268 patients with 
either post-necrotic or portal cirrhosis $15 \%$ had had syphilis. Finally, in 1965, Manderson et al., who were reviewing forty-nine cases of hepatic carcinoma, most of which were associated with cirrhosis, observed that five of the forty-nine $(10 \%)$, had had treatment for syphilis in the past.

As can be seen, over the last 100 years the incidence of syphilis in cirrhosis has mostly lain between 10 and $20 \%$, and the figure of $12.5 \%$ in our own series agrees well with this. The question is: what precisely is the reason for this seemingly unchanging statistical link between the two diseases? Clearly, it is important first of all to examine what associated conditions could be found in the syphilitic patient which in themselves might lead to liver damage. Prominent among these is, of course, the consumption of alcohol. The role of this agent in the production of cirrhosis is now firmly established and needs no further amplification here. Thus, the incidence of alcoholism in those series quoted above in which it has been reported has varied between 22 and $56 \%$. Schumacher found that syphilis and alcoholism were combined in $11 \%$ of his autopsy cases, whereas among his control series neither of the two alcoholics had been syphilitic. Ratnoff \& Patek (1942) calculated the chance association of alcoholism with syphilis and found that it was the same as the actual association in their own series. Among the thirty-two syphilitic cirrhotics of Fleming \& Snell (1942), seventeen $(56 \%)$, were alcoholics. MacDonald \& Mallory (1958) analysed twenty-six of their fortythree cirrhotic patients with syphilis for alcoholism and found that eleven $(42 \%)$ had drunk to excess. Wells \& Lundberg (1963), in their series of fifteen syphilitics with cirrhosis and hepatoma, noted the combination in nine. With the exception of these few instances, however, there is no information in the literature correlating the two conditions. Of our own patients, D.P. and E.F. had drunk alcohol to excess, while the incidence of alcoholism in the total group of cirrhotics is $30 \%$. From this, it is readily apparent that the occurrence of alcoholism in the two syphilitics is no more than can be accounted for by chance.

The next major question pertinent to any discussion on syphilis and cirrhosis is the role played by viral hepatitis. Although parenteral therapy for syphilis was first employed in the early 1920 s, it was not realized until much later that hepatitis could be transferred from one patient to another, not only in the treatment of syphilis, but by all other kinds of injection therapy (Memorandum prepared by the Medical Officers of the Ministry of Health, 1943). Further, with the increasing use of intravenous arsenicals, the syphilitic was at very great risk from serum hepatitis as compared with the general population, and Sheehan (1944) reported that in one clinic alone, 100 of 200 patients developed jaundice following arsenical therapy. Likewise, Salaman et al. (1944) showed that $37-68 \%$ of patients became jaun- $c$. diced when treated with improperly sterilized $\vec{\Rightarrow}$ syringes, as was usual in venereal disease clinics of $\stackrel{5}{\rightarrow}$ the time, compared with only $5 \%$ if due care was taken. Histological evidence was provided by Dible, 음 McMichael \& Sherlock (1943) to show that the liver lesion in arsenical jaundice was indistinguishable $\mathbb{Q}$ from that due to transfusion and infective hepatitis. is Of our patients, cases W.B. and A.L. had received injection therapy for syphilis, and case E.F. had had an illness highly suggestive of infective hepatitis. Thus, half of this small series might well have had hepatitis, and the latter might well have led to their developing cirrhosis. The importance of viral hepatitis in the aetiology of cirrhosis, however, is not yet fully defined. Although several workers have shown by or serial liver biopsies that an attack of hepatitis can $\infty$ lead to the development of cirrhosis within 5 years 9 (Sherlock, 1948; Krarup \& Roholm, 1941; Kunkel or \& Labby, 1950; Klatskin, 1958), the evidence against the possibility of this happening any more than $\vec{O}$ extremely rarely is quite impressive. Several followup studies on the sequelae of massive outbreaks of $\overrightarrow{0}$ hepatitis have been undertaken but have failed to $\Phi$ show persisting liver damage in any but a negligible $\overrightarrow{\vec{\theta}}$ proportion (Zieve et al., 1953; Neefe et al., 1958 Cullinan, King \& Rivers, 1958; Nefzger \& Chalmers. 1963; Chuttani et al., 1966). It is unlikely that thi question will finally be decided before better methods of diagnosing viral infection are available, and until such time the significance of hepatitis in the aetiology of cirrhosis must remain in doubt.

Ratnoff \& Patek in 1942, examining the association of syphilis with cirrhosis, pointed out that no final conclusions could be drawn in the absence of information about the incidence of syphilis in a comparable series, its incidence in alcoholics without cirrhosis, and the incidence of cirrhosis among syphilitics. Twenty-six years later, there is still no answer to these questions, and our series certainly suffers, as all others have done before it, from the lack of a satisfactory control group. Thus, although on commonsense grounds it seems most uhlikely that $12.5 \%$ of the general population have had syphilis, its actual incidence is not known. The figures from treatment centres in this country during the First and Second World War years o certainly showed a marked rise at those times (Paul, $N$ 1964), but they still do not tell us the total number of infected persons as, in the first place, not everyone $\underset{-}{\sigma}$ seeks treatment at a public centre, and secondly, no 0 account has been taken of those becoming infected $\overparen{D}$ while stationed abroad. As a result, one can only $\stackrel{\oplus}{?}$ say that a man who was in the Armed Forces during either war is more likely to have contracted syphilis 
than at any other time, but what proportion of today's male population has actually had the disease in the past is impossible to assess. As far as females are concerned, the routine serological tests done at antenatal clinics provide a satisfactory solution, but probably blood transfusion centres furnish the only comparable situation in which such tests are routinely done on males. In the South West region approximately 30,000 male donors are seen every year, their ages ranging from 18 to 65 . The results show that five to six cases were found to have a positive WR due to syphilis in every year since 1962, or an incidence of $0.02 \%$ (Tovey, G. H., Medical Director S.W. Blood Transfusion Service, personal communication, 1967). It is to be expected, however, that this figure is lower than would be found in a true random sample, as on the whole persons who have had a venereal disease may well be reluctant to become blood donors. Nevertheless, it gives us a very rough indication of how low the probable incidence of past infection with syphilis is in the general population.

In conclusion, although we cannot explain the association of syphilis with cirrhosis, nevertheless, it seems to us that there is a significant association and that this warrants the use of routine serological testing on all cirrhotic patients, particularly male. Such a procedure would not be merely of academic importance, as we found that three, or a half of our patients, had never received treatment for their infection, and one of them had progressed to tertiary syphilis.

\section{References}

Bockus, H.L. (1965) Gastroenterology, 2nd edn, Vol. III, pp. 463-7. Saunders, Philadelphia.

Boles, R.S. \& ClaRK, J.H. (1936) The role of alcohol in cirrhosis of the liver. J. Amer. med. Ass. 107, 1200.

Chuttani, H.K., Sidhu, A.S., Wig, K.L., GuPta, D.N. \& Ramalingswami, V. (1966) Follow up study of cases from the Delhi epidemic of infectious hepatitis of 1955-6. Brit. med. J. 2, 676.

Cullinan, E.R., King, R.C. \& Rivers, J.S. (1958) The prognosis of infective hepatitis. Brit. med. J. 1, 1315.

Dible, J.H., McMichael, J. \& Sherlock, S. (1943) Pathology of acute hepatitis: aspiration biopsy studies of epidemic, arsenotherapy, and serum jaundice. Lancet, ii, 402.

EDItoRial (1967) Brit. med. J. 2, 394.

Evans, N. \& Gray, P.A. (1938) Laennec's cirrhosis. $J$. Amer. med. Ass. 110, 1159.

Fleming, R.G. \& SNell, A.M. (1942) Portal cirrhosis with ascites: an analysis of $\mathbf{2 0 0}$ cases with special reference to prognosis and treatment. Amer. J. dig. Dis. 9, 115.

FreRICHS, F.T. (1861) A Clinical Treatise on Diseases of the Liver, Vol. II, p. 34. New Syden. Soc., London.

KLATSKIN, G. (1958) Subacute hepatic necrosis and postnecrotic cirrhosis due to anicteric infections with the hepatitis virus. Amer. J. Med. 25, 333.

KNIGHT, A \& WilkInson, R.D. (1963) The clinical significance of the biological false positive serological reactor: a study of 113 cases. Can. med. Ass. J. 88, 1193.
KraRUP, N.B. \& Roholm, K. (1941) The development of cirrhosis of the liver after acute hepatitis, elucidated by aspiration biopsy. Acta med. scand. 108, 306.

Kunkel, H.G. \& LABBY, D.H. (1950) Chronic liver disease following infectious hepatitis. II. Cirrhosis of the liver. Ann. intern. Med. 32, 433.

HaHn, R.D. (1943) Syphilis of the liver. Amer. J. Syph. Gonorrhoea vener. Dis. 27, 529.

LE Duc, D.M. (1929) A study of atrophic cirrhosis of the liver in relationship to syphilis. Ann. intern. Med. 2, 932.

MacDonald, R.A. \& Mallory, G.K. (1958) The natural history of postnecrotic cirrhosis. Amer. J. Med. 24, 334.

Mandeson, W.G., Patrick, R.S. \& Peters, E.E. (1965) Primary carcinoma of liver, a survey of cases admitted to Glasgow Royal Infirmary during 1949-1963. Scott. med. J. 10, 60 .

Memorandum PREPaRed BY THE MEdical OfFicers OF THE Ministry OF Health (1943) Homologous serum jaundice. Lancet, i, 83.

MiYAI, K. \& RuebneR, B.H. (1963) Acute yellow atrophy, cirrhosis, and hepatoma. Arch. Path. 75, 609.

MOORE, J.E. (1956) Venereology in transition. Brit. J. vener. Dis. 32, 217.

Neefe, J.R., Gambescia, J.M., KuRtz, C.H., Smith, H.D., Beebe, G.W., Jablon, S., Reinhold, J.G. \& Williams, S.C. (1955) Prevalence and nature of the hepatic disturbance following acute viral hepatitis with jaundice. Ann. intern. Med. 43, 1.

Nefzger, M.D. \& Chalmers, T.C. (1963) The treatment of acute infectious hepatitis. Amer. J. Med. 35, 299.

Paul, H. (1964) The Control of Disease, pp. 257-60. Livingstone, Edinburgh.

PoPPER, H. \& SChAFFNer, F. (1957) Liver: Structure and Function, pp. 562-4. McGraw-Hill, New York.

RATNOFF, O.D. \& PATEK, A.J. (1942) The natural history of Laennec's cirrhosis of the liver. Medicine (Baltimore), 21, 207.

Salaman, M.H., Williams, D.I., King, A.J. \& Nicol, C.S. (1944) Prevention of jaundice resulting from antisyphilitic treatment. Lancet, ii, 7.

Schumacher, G. A. (1937) Causative factors in the production of Laennec's cirrhosis with special reference to syphilis. Amer. J. med. Sci. 194, 693.

ShAPIRo, E. \& WeINER, H. (1951) The diagnosis of tertiary syphilis twenty-five years after McCrae. Amer. J. med. Sci. 222, 494.

SHEEHAN, H.L. (1944) Epidemiology of infective hepatitis. Lancet, ii, 8.

SHERLOCK, S. (1948) Post-hepatitis cirrhosis. Lancet, i, 817.

SHERLOCK, S. (1963) Diseases of the Liver and Biliary System, pp. 536-8. Blackwell Scientific Publications, Oxford and Edinburgh.

Stokes, J.H., BeERman, H. \& INGRAham, N.R. (1945) Modern Clinical Syphilology, pp. 846-92. Saunders, Philadelphia.

Symmers, D. (1916) Anatomic lesions in late acquired syphilis. J. Amer. med. Ass. 66, 1457.

Symmers, D. \& Spain, D.M. (1946) Hepar lobatum. Arch. Path. 42, 64.

Wells, R.F. \& LuNdBerg, G.D. (1963) Hepatoma: review of 43 cases with comments of syphilis as an aetiologic factor. Gastroenterology, 44, 598.

YeNikomshian, H.A. (1934) Non-alcoholic cirrhosis of the liver in the Lebanon and Syria. J. Amer. med. Ass. 103, 660.

Zieve, L., Hill, E., Nesbitt, S. \& Zieve, B. (1953) The incidence of residuals of viral hepatitis. Gastroenterology, 25, 495 . 